\title{
Biovigilância no processo de doação de órgãos e tecidos durante a pandemia: desafios para o enfermeiro
}

\author{
Biovigilance in the process of organ and tissue donation during the pandemic: challenges for nurses \\ Biovigilancia en el proceso de donación de órganos y tejidos durante la pandemia: desafíos para el \\ enfermero
}

Sibele Maria Schuantes Paim ${ }^{1}$ (D) Neide da Silva Knihs ${ }^{2}$ (1) João Luis Erbs Pessoa ${ }^{3}$ (1)

Aline Lima Pestana Magalhães ${ }^{2}$ (1) Laísa Fischer Wachholz ${ }^{2}$ (1) Patricia Treviso ${ }^{4}$ (1)

1.Universidade Federal de São Paulo. São Paulo, SP, Brasil.

2.Universidade Federal de Santa Catarina. Florianópolis, SC, Brasil.

3.Secretaria Estadual da Saúde do Estado de São Paulo, Central Estadual de Transplantes do Estado de São Paulo. São Paulo, SP, Brasil.

4.Universidade do Vale dos Sinos, Escola de Saúde. Porto Alegre, RS, Brasil.
Autor correspondente:

Sibele Maria Schuantes Paim.

E-mail: sibele.schuantes@hotmail.com.

\section{Recebido em 02/03/2021.}

Aprovado em 26/05/2021.

\begin{abstract}
Resumo
Objetivo: identificar as estratégias desenvolvidas pelo enfermeiro capazes de manter a biovigilância no processo de doação de órgãos e tecidos a fim de minimizar o risco de transmissão da COVID-19 entre doadores, receptores e equipes de saúde. Método: pesquisa exploratória, com abordagem qualitativa, apoiada no referencial teórico sobre a biovigilância da Agência Nacional de Vigilância Sanitária. Realizou-se a coleta de dados por meio de formulário on-line composto por questões abertas. Participaram 52 enfermeiros atuantes nas estruturas do Sistema Nacional de Transplantes. Os dados foram analisados pela Análise de Conteúdo. Resultados: identificou-se que o monitoramento e o controle no processo de doação, embasados na investigação clínica do potencial doador e na investigação familiar e comunitária, bem como a modificação da cultura de segurança na instituição, por meio da elaboração de protocolos e diretrizes para o cuidado do potencial doador, foram estratégias elaboradas pelo enfermeiro durante a pandemia com o objetivo de manter a segurança do paciente. Conclusão e implicações para a prática: as estratégias desenvolvidas pelos enfermeiros foram o monitoramento e o controle dos possíveis riscos relacionados com a contaminação do potencial doador pelo vírus SARS-CoV-2 e a modificação da cultura de segurança a partir da elaboração e implantação de protocolos, de modo a assegurar a continuidade da doação e o transplante de órgãos e tecidos, garantindo a segurança e a qualidade nesse processo.
\end{abstract}

Palavras-chave: Infecções por Coronavírus; Segurança do Paciente; Obtenção de Tecidos e Órgãos; Transplantes; Enfermagem.

\begin{abstract}
Objective: to identify the strategies developed by nurses capable of maintaining biovigilance in the process of organ and tissue donation in order to minimize the risk of transmission of COVID-19 among donors, recipients and health care teams. Method: an exploratory research, with a qualitative approach, supported by the theoretical framework on biovigilance of the Brazilian Health Regulatory Agency. Data were collected using an online form composed of open questions. Fifty-two nurses who work in the structures of the National Transplant System participated. The data was analyzed by Content Analysis. Results: it was identified that the monitoring and control of the donation process, based on the clinical investigation of the potential donor and on the family and community investigation, as well as the modification of the safety culture in the institution, through the development of protocols and guidelines for the care of the potential donor, were strategies developed by nurses during the pandemic in order to maintain patient safety. Conclusion and practice implications: the strategies developed by the nurses were the monitoring and control of possible risks related to the contamination of the potential donor by the SARS-CoV-2 virus and the modification of the safety culture through the development and implementation of protocols, in order to ensure the continuity of donation and transplantation of organs and tissues, ensuring safety and quality in this process.
\end{abstract}

Keywords: Coronavirus Infections; Patient Safety; Tissue and Organ Procurement; Transplants; Nursing.

\section{Resumen}

Objetivo: identificar las estrategias desarrolladas por el enfermero capaces de mantener la biovigilancia en el proceso de donación de órganos y tejidos para minimizar el riesgo de transmisión de COVID-19 entre donantes, receptores y equipos de salud. Método: investigación exploratoria con enfoque cualitativo, sustentada en el marco teórico sobre biovigilancia de la Agencia Nacional de Vigilancia Sanitaria. Los datos se recopilaron a través de un formulario en línea compuesto por preguntas abiertas. Participaron 52 enfermeros que laboran en las estructuras del Sistema Nacional de Trasplantes. Los datos se analizaron mediante análisis de contenido. Resultados: se identificó que el monitoreo y control en el proceso de donación, basado en la investigación clínica del potencial donante y en la investigación familiar y comunitaria, así como la modificación de la cultura de seguridad en la institución, mediante el desarrollo de protocolos y guías de el cuidado del donante potencial, fueron estrategias desarrolladas por el enfermero durante la pandemia con el fin de mantener la seguridad del paciente. Conclusión e implicaciones para la práctica: las estrategias desarrolladas por los enfermeros fueron el monitoreo y control de posibles riesgos relacionados con la contaminación del potencial donante por el virus SARS-CoV-2 y la modificación de la cultura de seguridad a partir del desarrollo e implementación de protocolos, con el fin de asegurar la continuidad de la donación y trasplante de órganos y tejidos, garantizando la seguridad y calidad en este proceso.

Palabras clave: Infecciones por Coronavirus; Seguridad del Paciente; Obtención de tejidos y órganos; Trasplantes; Enfermería. 


\section{INTRODUÇÃO}

O mundo e o Brasil estão diante de uma situação desafiadora: desde março de 2020, a Organização Mundial da Saúde (OMS) considera a COVID-19, doença causada pelo SARS-CoV-2, uma das infecções por Coronavírus, uma pandemia. Diante desse cenário, equipes de saúde de todo o mundo têm buscado estratégias efetivas no sentido de minimizar o contágio e a propagação dessa doença ${ }^{1,2}$.

Mesmo frente a esforços imensuráveis de organizações governamentais e não governamentais, a doença progrediu em muitos países de maneira avassaladora, contaminando e matando muitas pessoas e profissionais da saúde ${ }^{3-6}$.

Devido a isso, incertezas a respeito de como realizar a assistência à saúde segura surgem diariamente, principalmente quando se trata da obtenção de tecidos e órgãos para transplantes. Fez-se necessário compreender todos os mecanismos biológicos envolvidos e a melhor maneira de garantir a segurança dos potenciais doadores de órgãos e tecidos, assim como dos receptores. Nesse cenário de saúde instituído pela COVID-19, a sensibilidade do tema de segurança do paciente, sobretudo relacionado ao processo de doação e transplante de órgãos e tecidos, tornou-se evidente sob a ótica de como manter o cuidado seguro, efetivo e de qualidade ao vivenciarem-se momentos ímpares como este. Diante desse contexto, a segurança no processo de doação de órgãos e tecidos surge como premissa para a continuidade dos procedimentos de transplantes.

Conceitualmente, a OMS define a segurança do paciente como a redução dos riscos ao mínimo aceitável de danos desnecessários associados à assistência ${ }^{7}$. Em relação ao processo de doação e transplante de órgãos, tecidos e células, a Agência Nacional de Vigilância Sanitária (Anvisa) denomina incidente a ocorrência de desvio dos procedimentos operacionais ou das políticas de segurança relacionados à retirada, à avaliação, ao processamento, ao armazenamento e à distribuição de células, tecidos e órgãos. Tais situações podem ser detectadas antes ou após a doação ou transplante/infusão/enxerto/implante e podem ou não levar à transmissão de enfermidade, à morte, ao risco à vida, a deficiências, a incapacidades, à prolongação da enfermidade ou à hospitalização do receptor ou doador vivo ${ }^{8}$.

A Resolução de Diretoria Colegiada (RDC) n³39/2020, da Anvisa, propõe um conjunto de ações de monitoramento e controle que abrange todo o ciclo de células, tecidos e órgãos humanos, desde a doação até a evolução clínica do receptor e do doador vivo. Além disso, tem como objetivo a melhoria da qualidade dos processos relacionados ao ciclo das células, tecidos e órgãos humanos, em alinhamento com o Programa Nacional de Segurança do Paciente ${ }^{9}$.

Destaca-se que todas as etapas do processo de doação estão sob a responsabilidade dos profissionais da saúde, desde o gerenciamento da avaliação e validação do Potencial Doador (PD), passando pela extração de células, tecidos e órgãos humanos, até o processamento, acondicionamento, armazenamento, transporte, disponibilização/distribuição, uso terapêutico e seguimento dos receptores e doadores vivos de células, tecidos e órgãos humanos ${ }^{9,10}$.

Diante desses conceitos de monitoramento e gestão das etapas do processo de doação de órgãos e tecidos e, ainda, considerando a realidade da pandemia e as orientações da OMS, do Ministério da Saúde, do Sistema Nacional de Transplante (SNT) e da Associação Brasileira de Transplantes de Órgãos (ABTO), ressalta-se que, durante a validação de doadores de órgãos e tecidos, os indivíduos poderão ser classificados como "doador com contraindicação relativa" ou "doador com contraindicação absoluta", não sendo possível classificar um doador como "doador sem contraindicação" enquanto durar o estado de pandemia de SARS-CoV-2 $2^{3,11,12}$.

Frente a esse cenário, o enfermeiro, enquanto principal gestor e membro das Centrais Estaduais de Transplantes (CET), da Organização de Procura de Órgãos (OPO) e da Comissão Intra-hospitalar de Doação de Órgãos e Tecidos para Transplantes (CIHDOTT), assume um grande desafio: dar continuidade à identificação e validação do potencial doador de órgãos e tecidos em tempos de pandemia, uma vez que o número de pacientes em lista de espera mantém-se elevado e os transplantes não podem parar ${ }^{11}$. Ainda se exige, do profissional, uma atitude proativa para a tomada de decisão e a continuidade da assistência de Enfermagem segura diante de tantos desafios ${ }^{13}$.

Tal realidade, imposta pela situação da saúde mundial, desafia o profissional enfermeiro, inserido no processo de doação de órgãos e tecidos, a assumir o compromisso e a responsabilidade de minimizar a infecção cruzada entre os membros da equipe e os pacientes portadores do vírus, assintomáticos e não diagnosticados com a COVID-196. Dessa forma, cabe ao enfermeiro a criação de estratégias que tenham impacto na minimização de danos à saúde dos receptores, disponibilizando órgãos saudáveis e viáveis.

Nessa perspectiva, compreende-se a importância de conhecer a vivência dos enfermeiros, bem como as estratégias utilizadas por eles diante do cenário de COVID-19. Torna-se fundamental, considerando que esse é um profissional que assume muitos papéis no processo de doação, com pouca valorização, visibilidade e crédito pelo sucesso da doação e do transplante no Brasil, abordar essa temática e mostrar as contribuições desse profissional no cenário de doação de órgãos e tecidos em tempos de pandemia, uma vez que 2020 foi o ano da Enfermagem e o ano em que o enfermeiro esteve diante de tantos desafios.

Portanto, este estudo tem como questão norteadora: "Quais estratégias estão sendo desenvolvidas pelo enfermeiro capazes de manter a biovigilância no processo de doação de órgãos e tecidos a fim de minimizar o risco de transmissão da COVID-19 entre doadores e receptores?".

O objetivo é identificar as estratégias desenvolvidas pelo enfermeiro capazes de manter a biovigilância no processo de doação de órgãos e tecidos a fim de minimizar o risco de transmissão da COVID-19 entre os doadores, os receptores e as equipes de saúde. Certamente, tais informações podem apoiar 
os demais colegas da equipe de saúde, fortalecer a segurança no processo de doação e transplantes, além de empoderar e respaldar o enfermeiro enquanto profissional atuante nesse processo.

\section{MÉTODO}

Trata-se de uma pesquisa exploratória, com abordagem qualitativa, apoiada pelo referencial teórico-metodológico da Análise de Conteúdo, em que os dados foram codificados e analisados sob a ótica da RDC no 339/2020 da Anvisa ${ }^{9,14}$. Escolheu-se essa RDC por reger nacionalmente o processo de doação e transplante de órgãos e tecidos no que diz respeito à biovigilância. Trata-se de um marco conceitual e legal que impõe a análise, a notificação e o monitoramento de processos e procedimentos conduzidos pelos profissionais da saúde atuantes no SNT como forma de reduzir os riscos e os eventos adversos, contribuindo para a segurança do paciente 9 .

No escopo da pesquisa, buscou-se focar nas ações, nos procedimentos e processos do enfermeiro como gestor do cuidado no processo de doação e transplante, não explorando diretamente as notificações dos eventos adversos.

A pesquisa foi realizada com 52 enfermeiros atuantes nas estruturas do SNT (CET, OPO e CIHDOTT). O critério de inclusão foi estabelecido como: enfermeiros atuantes na área assistencial do SNT em todo território nacional. Foram excluídos os enfermeiros que estavam em férias ou afastados, bem como aqueles que estavam substituindo, temporariamente, algum profissional no momento da coleta.

A coleta de dados foi realizada entre maio e junho de 2020 utilizando-se um formulário on-line, elaborado pelos pesquisadores e sediado na plataforma Google Forms ${ }^{\circledR}$, constituído de dados de caracterização sociodemográfica, como idade, gênero, estado civil, religião, estado onde trabalha e formação acadêmica, bem como por três questões abertas (Quadro 1), que objetivavam identificar as estratégias dos enfermeiros em relação à segurança do processo de doação de órgãos e tecidos no contexto da pandemia de COVID-19. O formulário foi previamente testado por dois profissionais atuantes no SNT, o que possibilitou ajustes nas questões abertas. Os mesmos não foram incluídos no estudo.
Primeiramente, os pesquisadores enviaram o link de acesso, via e-mail, para os coordenadores das CET dos Estados brasileiros juntamente com a explicação da pesquisa. Na sequência, os coordenadores encaminharam-no aos demais enfermeiros vinculados à CET para responderem à pesquisa. Todos os participantes concordaram com o Termo de Consentimento Livre e Esclarecido disponível na primeira página do instrumento de coleta de dados. Os participantes responderam ao formulário de maneira aleatória, considerando o interesse pela pesquisa. Não foi calculada a amostra.

Para a análise dos dados, utilizou-se o referencial da Análise de Conteúdo preconizado por Laurence Bardin. Esse método consiste em três etapas primordiais: 1) pré-análise: constituída da leitura flutuante das respostas obtidas a fim de realizar o primeiro reconhecimento dos dados e a formulação de indicadores de categorias; 2) exploração do material: fase de leitura exaustiva, buscando categorizar os dados obtidos conforme os indicadores já identificados e 3) tratamento dos dados obtidos e interpretação, em que, após estabelecidas as categorias, se infere com base nas informações obtidas em comparação com outros estudos semelhantes realizados no campo temático ${ }^{14}$.

Destaca-se que cada autor realizou a leitura e apropriou-se das respostas dos formulários. Ao final, todos compartilharam as categorias identificadas individualmente e estabeleceram uma concordância entre as análises de maneira conjunta. No caso de alguma discordância, realizou-se uma discussão aprofundada até ser possível atingir a concordância. Portanto, foram estabelecidas duas categorias e quatro subcategorias com base no referencial teórico da Anvisa.

As respostas dos participantes encontram-se identificadas com a letra $E$ seguida da ordem em que a resposta foi enviada, por exemplo: E1, E2 e, assim, sucessivamente.

Ressalta-se que os pesquisadores apresentam experiência no campo acadêmico e assistencial no que diz respeito ao processo de doação e transplante de órgãos e tecidos, quatro deles com cerca de 20 anos na condução desse processo, o que garantiu a validade para a elaboração do formulário e a interpretação dos dados obtidos.

Quadro 1. Questões abertas utilizadas para a coleta de dados.

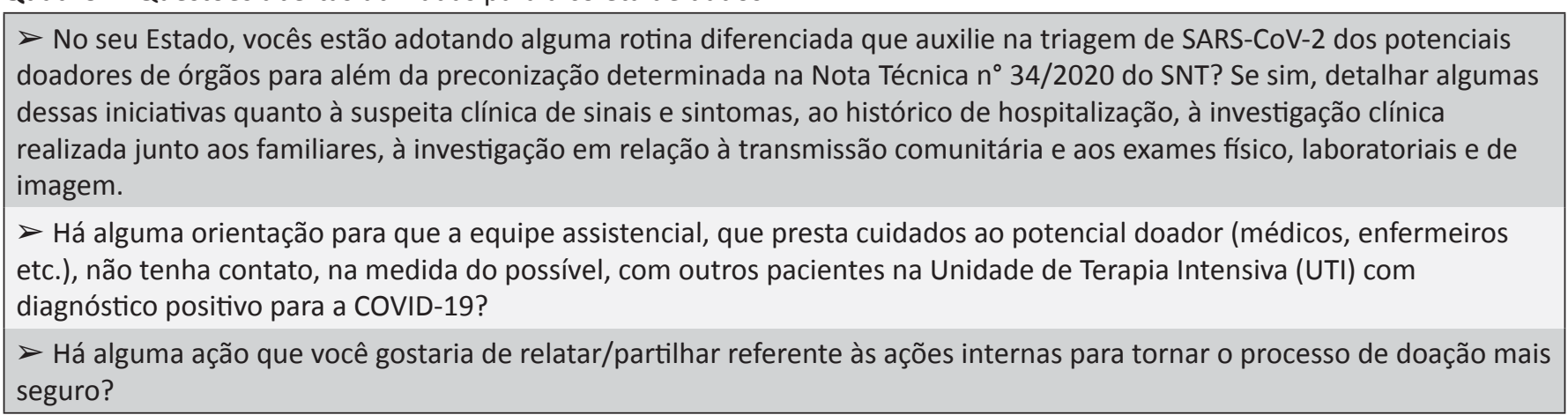

Fonte: Elaborado pelos autores, 2020. 
A pesquisa respeitou os aspectos éticos envolvendo seres humanos, sendo norteada pelas Resoluções nำ 466/12 e no 510/2016 do Conselho Nacional de Saúde e aprovada pelo Comitê de Ética em Pesquisa da Universidade Federal de Santa Catarina sob o Parecer ํㅜ 4.049.851 e Certificado de Apresentação e Apreciação Ética ํㅡㄴ 31782620.5.0000.0121.

\section{RESULTADOS}

Participaram da pesquisa 52 profissionais enfermeiros que atuam no SNT (CET, OPO e CIHDOTT). Desses, 82,7\% são do gênero feminino; $57,7 \%$, casados; $51,9 \%$, católicos; $92,3 \%$ possuem alguma pós-graduação e $90 \%$ são formados e atuam há mais de dez anos com o processo de doação de órgãos e tecidos.

Elaboraram-se, considerando a RDC nํ 339/2020 da Anvisa, duas categorias com suas respectivas subcategorias, conforme apresentado na Figura 1.

A categoria "Monitoramento e controle no processo de doação" representou o esforço do profissional enfermeiro no sentido de propor ajustes no processo de doação de órgãos e tecidos, principalmente na identificação, validação, seleção e notificação do potencial doador à CET. Revelou, ainda, o empenho do enfermeiro e sua equipe quanto ao rastreamento e monitoramento envolvendo questões clínicas, sociais, físicas e laboratoriais no sentido de monitorar, controlar e investigar os fatores que possam indicar um possível contato do potencial doador com a COVID-19.

Na subcategoria "Investigação clínica do potencial doador", os enfermeiros utilizaram a sua competência clínica na prática assistencial para fazer a avaliação do potencial doador, voltandose para o exame físico detalhado e para a avaliação dos exames laboratoriais e de imagem no intuito de garantir a segurança no processo de seleção desse paciente. Abaixo, alguns exemplos de respostas, fornecidas pelos enfermeiros, que subsidiaram a construção dessa subcategoria.

Testamos todos os potenciais doadores, mesmo sem dados clínicos e/ou epidemiológico (sic) para COVID-19. Não importa, queremos ter um processo seguro. (E35)

A coleta para o exame do PCR é realizada pelo aspirado traqueal e a operacionalização desta (sic) coleta tem se mostrado mais segura aos profissionais de Enfermagem do que o swab, visto que os pacientes utilizam sistema fechado de aspiração. (E27)

Realizamos monitoramento de febre com gráfico diário e saturação (correlacionando com as imagens e auxílio da equipe médica. (E24)

Investigamos febre, saturação baixa, sinais de arritmias, taquicardia e lesões de pele. (E43)

Principalmente, a febre. Rastreamos a curva da temperatura. Mas também avaliamos alterações cardíacas e pulmonares. (E45)

Principalmente, a parte respiratória (secreção, ausculta pulmonar, perfusão periférica, saturação). (E52)

Na subcategoria "Investigação familiar e comunitária do potencial doador", identifica-se a preocupação do enfermeiro em compreender o caminho percorrido pelo paciente até tornarse um doador. A atenção a esse detalhe decorre da tentativa de certificar-se ou de minimizar o risco de o paciente ter tido contato com outros indivíduos contaminados pelo SARS-CoV-2.

O profissional enfermeiro criou, como estratégia, a rastreabilidade e a verificação junto aos familiares e profissionais da saúde do percurso até o atendimento final. Para isso, realizase uma investigação detalhada do itinerário terapêutico do PD
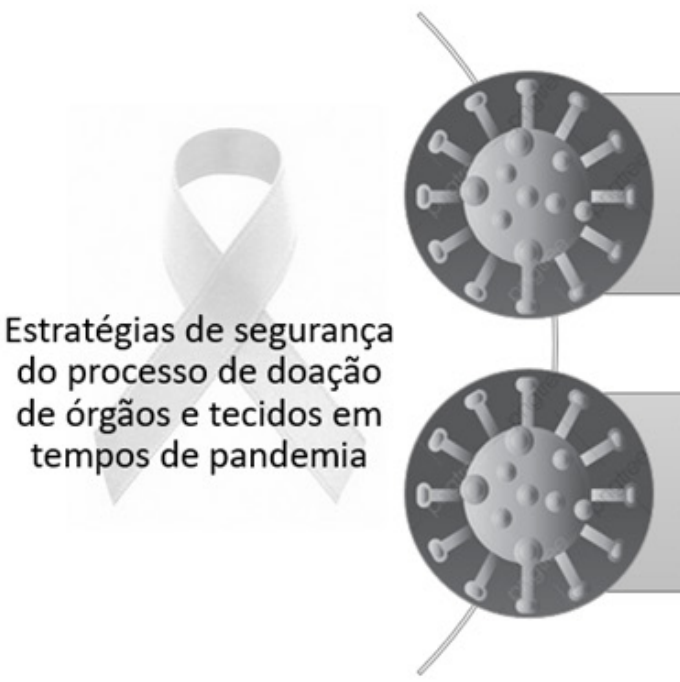

CATEGORIA 1: MONITORAMENTO E CONTROLE NO PROCESSO DE DOAÇÃO

- Investigação clínica do potencial doador

- Investigação familiar e comunitária do potencial doador

Figura 1. Representação gráfica das categorias e subcategorias.

Fonte: Elaborado pelos autores, 2020. 
pelas instituições de saúde, buscando identificar a existência de internações prévias e o tempo de internação nas unidades de saúde.

Solicitado à (sic) equipe de saúde que, em todos os contatos com a família, desenvolve-se (sic) a investigação clínica, especificadamente (sic) sobre a COVID-19. (E1) Investigamos se o paciente teve alguma internação prévia a essa nos últimos dias. (E12)

Acompanhamos, pregressamente, o histórico de internação juntamente com o histórico de outra instituição, se houve transferência, bem como acompanhamos diariamente após estar na busca ativa. (E25)

Buscamos saber por onde o paciente passou até chegar na Unidade de Terapia Intensiva onde está internado, se ele passou por unidades de saúde que possa (sic) ter tido contato com casos confirmados ou suspeito (sic) de COVID-19. Quanto tempo ficou internado pelos locais por onde passou antes de chegar à Unidade de Terapia Intensiva. (E34)

Antes de notificar o PD, desenvolvemos uma discussão do caso entre médico da Comissão Hospitalar de Transplante e Central Estadual de Transplante. (E31)

Investiga-se, com a equipe que cuidou do paciente até o momento, se há alguma alteração ou algum indicativo de sinais de COVID-19. Ainda se faz uma busca no prontuário, identificando tudo que foi registrado pela equipe, até o momento, sobre o paciente. (E53)

Ainda, como estratégia para apoiar a seleção do potencial doador antes de notificar à CET, os enfermeiros investigam, junto aos familiares, a rotina de cuidados domiciliares e sociais para a prevenção da COVID-19.

Questiona-se quais medidas os familiares e o PD adotaram e adotam para a prevenção da COVID-19, bem como qual era a rotina do $P D$, como eles estão procedendo na quarentena, além de avaliar a quantidade de pessoas que vivem na residência [e] se há casos suspeitos na família ou comunidade. (E7)

Questionamos como estava o PD antes da internação. Se estava mantendo o distanciamento social, quantas pessoas moravam juntas e se alguma ficou doente ou teve sintoma ou o (sic) COVID-19 nos últimos dias. (E19)

A "Cultura de segurança no processo de doação" é a segunda categoria e representa o envolvimento da equipe de saúde quanto à necessidade de mudanças frente à pandemia de COVID-19. Destaca, ainda, a necessidade de mudanças de normas, procedimentos e comportamentos relacionados à segurança do processo de doação de órgãos e tecidos.
Essa categoria sustenta-se na subcategoria "Valores, atitudes, competências e comportamentos da equipe". Os achados dessa subcategoria revelam a necessidade do enfermeiro em mostrar que as mudanças de atitudes e comportamentos, aliadas à competência da equipe, podem assegurar a continuidade da doação de órgãos, mesmo diante da crítica situação da saúde global.

Ao desenvolver estratégias que promovam a confiança da equipe da UTI e da CET, o enfermeiro fortalece o sistema, promove a responsabilização dos pares, para seguir o que the foi proposto, e proporciona novos aprendizados. As estratégias de mudanças relacionam-se com a rotina de cuidados ao PD e com a elaboração de protocolos para minimizar os riscos de transmissão da COVID-19 ao possível doador enquanto se aguarda a realização ou finalização do protocolo de Morte Encefálica (ME) ou a extração dos órgãos do PD.

Promovemos a mudança da rotina de cuidados, [a] partir da identificação do $P D$, esse paciente passa a ser cuidado por um único membro da equipe após o resultado do exame do PCR até a retirada dos órgãos. (E28)

Elaborado um questionário para ser preenchido junto aos familiares para segurança das informações, como, por exemplo, se o paciente teve contato com alguém com COVID-19, se viajou fora [do] Estado e de sua cidade em menos [de] 21 dias, dentre outras questões que são feitas. (E40)

Foi criado um protocolo com os exames e cuidados a serem seguidos pela equipe enquanto esse paciente aguarda o protocolo de ME e a retirada dos órgãos para minimizar o risco de transmissão do vírus SARS-CoV-2 para o PD. (E13)

Temos um protocolo para solicitação de exames do $P D$ na COVID-19; geralmente, é hemograma e tomografia, mantemos o mesmo em todos os $P D$, entretanto, se houver necessidade, solicitamos outros exames específicos. (E22)

Orientações e rotinas foram elaboradas no serviço que atuo para desenvolver qualquer assistência com o paciente, na verdade. Cuidados em transitar em áreas com COVID-19, utilizar todos os Equipamentos de Proteção Individual necessários para [a] proteção individual, cuidados no uso de elevadores (para não haver exposição), treinamento na paramentação e como retirar os EPIs sem ocorrer contaminação, uso criterioso de máscara, utilizando adequadamente a máscara indicada ao local que esteja, e até como se comportar fora do ambiente hospitalar, os cuidados em cada, (sic) com nossos familiares. (E18)

A outra subcategoria, intitulada "Comprometimento com a gestão da saúde e da segurança”, expõe a busca do enfermeiro para tornar esse processo o mais transparente e seguro possível em tempos de pandemia. Por meio das informações obtidas, é possível compreender que esse profissional transcende os 
muros de sua instituição para buscar informações em outros cenários de saúde na tentativa de fortalecer a segurança do processo de doação.

Além disso, o enfermeiro compreende que esse é um processo complexo, que envolve muitas pessoas, tanto na etapa da doação como na etapa do explante, em especial, os receptores. Assim, é fundamental que se busquem informações em todas as instâncias para assegurar que esse paciente não foi contaminado pelo vírus SARS-CoV-2, seja fazendo contato com a vigilância epidemiológica do município, seja com os profissionais que cuidaram do PD.

Ressalta-se a importância da liderança desse profissional na incorporação de novos protocolos institucionais, visando à segurança do processo. As falas revelam o percurso desse enfermeiro.

Buscamos fazer contato com a equipe da vigilância epidemiológica, identificando se a região do paciente é considerada uma área endêmica e se há casos próximos à (sic) casa do paciente ou no local de trabalho. (E16)

Entramos em contato com todos os profissionais que atenderam o paciente pelos locais onde ele passou. Se esteve em mais de uma instituição, fizemos contato com todas. (E44)

Elaboramos um instrumento para desenvolver informações que possam formar uma história clínica (sic) detalhada. (E37)

\section{DISCUSSÃO}

Em tempos de pandemia de COVID-19, o enfermeiro, enquanto profissional da saúde, enfrenta inúmeros desafios, os quais estão direcionados às condições de trabalho, à segurança pessoal, às alterações em fluxos de trabalho, aos ajustes nas políticas de saúde, aos novos profissionais nas instituições, às pressões diante do aumento da demanda, além da complexidade dos cuidados aos pacientes acometidos pela doença. Neste cenário de medo, dúvidas, inseguranças e novos desafios, o enfermeiro passa a enfrentar a necessidade da continuidade da assistência em saúde, tendo que assegurar a celeridade nos processos, a segurança e a efetividade ${ }^{15,16}$.

Ainda no cenário das instituições de alta complexidade, esse profissional procura dar continuidade ao processo de doação de órgãos e tecidos, uma vez que, para os pacientes que continuam em lista de espera, esse é o único tratamento. Tanto a OMS como as organizações governamentais e não governamentais apontaram caminhos para a segurança desse processo durante a pandemia por meio de notas técnicas, resoluções e recomendações ${ }^{3,11,12}$.

No contexto da segurança na doação de órgãos e tecidos, antes da confirmação da pandemia pela OMS, a Anvisa, por meio da RDC no 339/2020, tornou públicos os princípios e as orientações a profissionais da saúde sobre a biovigilância, de maneira a assegurar a continuidade de etapas transparentes desde a identificação do PD até o implante do órgão, com a perspectiva de aprimorar a qualidade dos processos relacionados ao ciclo de células, tecidos e órgãos humanos, em alinhamento com o Programa Nacional de Segurança do Paciente 9 .

Assim, diante da pandemia e frente às novas diretrizes da Anvisa, compreende-se que o profissional enfermeiro, enquanto gestor desse processo, está diante de momentos complexos para assegurar a continuidade e a segurança na doação de órgãos e tecidos. Os desafios no contexto da pandemia são inúmeros, envolvendo desde a identificação, seleção e notificação do potencial doador à CET até a logística, organização e avaliação do paciente que irá receber o órgão doado. As falas dos profissionais enfermeiros deixam claros os enfrentamentos da continuidade da doação de órgãos em tempos de pandemia de COVID-19, apontando a necessidade e a importância de cada sinal e sintoma clínico ser rastreado e investigado com muito tato e cuidado.

Nessa perspectiva, faz-se necessário que o profissional inicie, desde a busca ativa do possível doador de órgãos e tecidos, uma rigorosa investigação clínica do paciente, bem como uma investigação familiar e comunitária, além de rastrear, junto à equipe de saúde, situações clínicas, alterações hemodinâmicas, sinais e sintomas, além de outros achados que possam direcionar a sinais clínicos de COVID-193,11,12.

Neste estudo, são evidenciadas as ações do enfermeiro para promover etapas seguras na doação de órgãos frente à pandemia, uma vez que esse profissional busca seguir as recomendações para o monitoramento e o controle dos possíveis riscos relacionados com a contaminação do PD pelo SARSCoV-2. Nos discursos, os enfermeiros participantes mencionam ações de cuidado direcionadas a mapear, rastrear e monitorar quaisquer achados clínicos que possam indicar uma possível contaminação pelo vírus.

Vale salientar que esses profissionais aprimoram a vigilância por meio de informações clínicas junto a familiares e à comunidade na tentativa de identificar quais informações podem indicar o contato do PD com a COVID-19. Há uma verdadeira peregrinação do enfermeiro entre avaliar o registro nos prontuários, avaliar as alterações hemodinâmicas e rastrear e mapear cada caminho percorrido pelo paciente até a chegada na Unidade de Paciente Crítico (UCl). Em todos os momentos, essa investigação fica clara nos depoimentos coletados, evidenciando-se as estratégias realizadas para assegurar a qualidade e a segurança nesse processo.

O monitoramento de pacientes com sinais clínicos que podem indicar a COVID-19 é uma das ferramentas fundamentais na atual situação em que o Brasil se encontra na pandemia. $O$ processo de doação deve seguir cuidados rígidos e cautelosos. $O$ potencial doador somente poderá ser validado para a doação de órgãos e tecidos após uma investigação clínica e epidemiológica detalhada ${ }^{17}$.

Assim, compreende-se que entre as estratégias utilizadas pelo profissional estão o monitoramento e a investigação clínica e epidemiológica aliados ao raciocínio clínico. O raciocínio clínico mostrou-se como uma das estratégias indispensáveis 
do enfermeiro no processo de doação de órgãos durante a situação grave de pandemia, uma vez que reflete e articula as informações e evidências obtidas que possam indicar a ele e aos demais membros da equipe se o paciente pode, ou não, estar contaminado pelo vírus SARS-CoV-2 ${ }^{18}$.

O raciocínio clínico é desenvolvido pelo enfermeiro mediante o reconhecimento de evidências sobre a situação que está investigando, diferenciando-a de outras similares e concluindo o seu pensamento por meio de habilidades e competências clínicas. Para que o enfermeiro possa desenvolver essa estratégia em saúde e garantir um cuidado seguro e eficaz, é crucial que esteja sustentado em conhecimentos, habilidades e atitudes para a avaliação clínica do PD, bem como no conhecimento do processo de trabalho em que está atuando. O raciocínio clínico oportuniza a tomada de decisão rápida e segura, contribuindo para a autonomia, a liderança e a gestão do profissional enfermeiro ${ }^{18,19}$ Essa foi uma das estratégias ímpares adquiridas pelo enfermeiro para enfrentar essa nova realidade diante da pandemia. Nas falas, deixa-se transparecer a discussão realizada com a equipe de doação de transplantes da instituição e da CET.

Ainda, este estudo revela que o raciocínio clínico também está sendo utilizado como ferramenta e estratégia pelo enfermeiro e não apenas como instrumento investigativo. Mas, acima de tudo, é utilizado como instrumento capaz de guiar, orientar e assegurar a tomada de decisão de maneira efetiva, considerando as notas técnicas, as resoluções e as recomendações vigentes no Brasil quanto ao processo de doação de órgãos e tecidos durante a pandemia ${ }^{3,11,12}$, ao ponderar que os sinais e sintomas da COVID-19 podem gerar dúvidas e insegurança ao profissional enfermeiro, já que muitas das alterações hemodinâmicas apresentadas pelo paciente grave contaminado pelo vírus SARS-CoV-2 também são alterações comuns no possível e potencial doador devido à lesão neurológica irreversível ${ }^{20}$.

Diante dessa realidade, o estudo mostra outra estratégia adotada pelo enfermeiro: a alteração/readequação da cultura de segurança nas instituições. Os profissionais que atuam no processo de doação de órgãos e tecidos precisam compreender esse momento, considerando a pandemia da COVID-19 e abrindo espaço para novos aprendizados e mudanças. Mesmo que sejam profissionais com tempo significativo de exercício no processo de doação, o momento necessita de habilidades específicas em cada etapa desse processo. $\mathrm{O}$ estudo ainda revela que os profissionais enfermeiros utilizaram o apoio da gestão para assegurar a continuidade do processo, garantindo a segurança e a qualidade.

De acordo com a Anvisa, a cultura de segurança do paciente é definida como um produto de valores, atitudes, percepções e competências grupais e individuais que determina o padrão de comportamento e comprometimento de segurança da instituição, substituindo a culpa e a punição pela oportunidade de aprender com as falhas ${ }^{20}$. Frente ao processo de doação de órgãos e tecidos durante a pandemia de COVID-19, o enfermeiro está diante da necessidade de criar estratégias para fortalecer a segurança de todo o processo, a qual é direito do paciente, bem como o compromisso ético da equipe multiprofissional e da instituição de saúde ${ }^{10}$.

As falas do estudo deixam transparecer que a estratégia para auxiliar a mudança da cultura de segurança foram a elaboração e a implantação de novos protocolos, diretrizes e ferramentas de cuidados que apoiassem o enfermeiro na investigação junto a familiares e profissionais da saúde, além de ferramentas que asseguram a continuidade da assistência ao potencial doador, mesmo diante do risco de contaminação pelo vírus SARSCoV-2. A estratégia de utilização de protocolos de segurança do paciente é um estímulo para a prática assistencial segura e para o fortalecimento da cultura de segurança em cenários de cuidado 21,22 .

No contexto da pandemia de COVID-19, é fundamental que a equipe ajuste seus objetivos e condutas para dar continuidade à assistência segura. Conforme estabelecido pelo Decreto $\mathrm{n}$ ㅇ 9.175, de 18 de outubro de 2017, a equipe multiprofissional necessita ter condutas coerentes, realizar reuniões periódicas e manter contato contínuo a fim de alinhar os objetivos e alcançar as metas propostas. Ainda vale destacar que a RDC no 339/2020 apoia a implementação de protocolos, guias e manuais de boas práticas no processamento de células, tecidos e órgãos humanos para transplante, visando à garantia da qualidade e à segurança dos procedimentos prestados ${ }^{9,23}$.

O grave problema de saúde pública estabelecido pela pandemia refletiu na prática dos profissionais de forma que, para manter a assistência qualificada e segura, o enfermeiro necessitou ajustar o cuidado. Uma das competências do enfermeiro no processo de doação de órgãos e tecidos está direcionada à gerência do cuidado, envolvendo valores, conhecimentos, habilidades e ações condizentes com a natureza do trabalho ${ }^{24}$.

Assim, compreende-se que a gestão da saúde e da segurança está diretamente relacionada com a gestão de risco descrita na RDC n 339/2020, que preconiza a aplicação de políticas, procedimentos, condutas e recursos na identificação, na análise, na avaliação, na comunicação, no controle de riscos e em eventos adversos que afetem, dentre outros, a segurança ${ }^{9}$.

Diante do contexto da pandemia, o enfermeiro necessitou reorganizar suas condutas para investigar a possível contaminação de PD pelo vírus SARS-CoV-2, tendo como desafio principal assegurar a continuidade da assistência em cada etapa do processo de doação de órgãos e tecidos. Somado a isso, há a responsabilidade de garantir que cada etapa seja desenvolvida seguindo todos os parâmetros éticos e de segurança ponderados na legislação vigente. Por fim, ressalta-se que a instituição de protocolos, normas e rotinas auxiliam essa importante tarefa, tornando os processos de trabalho mais seguros para profissionais e pacientes ${ }^{3}$.

\section{CONCLUSÃO E IMPLICAÇÕES PARA A PRÁTICA}

As estratégias desenvolvidas pelos enfermeiros atuantes no SNT, capazes de manter a biovigilância no processo de doação de órgãos e tecidos em tempos de pandemia, abrangem 
o monitoramento e o controle de possíveis riscos relacionados com a contaminação do PD pelo vírus SARS-CoV-2, utilizando-se da investigação clínica e epidemiológica detalhada articulada ao raciocínio clínico.

Outra estratégia implementada foi a modificação da cultura de segurança, a partir da elaboração e da implantação dos protocolos, de modo a assegurar a continuidade da doação e do transplante de órgãos e tecidos, garantindo a segurança e a qualidade no processo, uma vez que o número de pessoas em lista de espera aguardando por um transplante não diminuiu.

A impossibilidade de um debate e a pouca profundidade das respostas são entendidas como limitações deste estudo.Tal situação está intrinsecamente relacionada ao contexto vivenciado na pandemia, principalmente quanto aos profissionais da saúde, que estão sobrecarregados com o aumento de trabalho e da carga horária. Entretanto, os resultados denotam a preocupação com a segurança e com a qualidade do trabalho realizado por esses profissionais em prol do paciente e do processo de doação e transplante.

Os resultados apresentados destacam as atividades realizadas pelos enfermeiros que visam a garantir a biovigilância no contexto da pandemia de COVID-19. É possível evidenciar, pelas falas dos enfermeiros, a mudança de atitudes e comportamentos, assim como o comprometimento desses profissionais em garantir a continuidade do processo de doação de órgãos e tecidos para transplantes de maneira segura e com qualidade. Ressalta-se que a presença do enfermeiro nesse contexto mostrou-se importante para a promoção da cultura de segurança do paciente.

\section{CONTRIBUIÇÕES DOS AUTORES}

Concepção e desenho do estudo: Sibele Maria Schuantes Paim. Neide da Silva Knihs. João Luis Erbs Pessoa. Aline Lima Pestana Magalhães. Laísa Fischer Wachholz.

Coleta de dados: Sibele Maria Schuantes Paim. Neide da Silva Knihs. João Luis Erbs Pessoa. Aline Lima Pestana Magalhães. Laísa Fischer Wachholz. Patricia Treviso.

Análise de dados: Sibele Maria Schuantes Paim. Neide da Silva Knihs. João Luis Erbs Pessoa. Aline Lima Pestana Magalhães. Laísa Fischer Wachholz. Patricia Treviso.

Interpretação dos resultados: Sibele Maria Schuantes Paim. Neide da Silva Knihs. João Luis Erbs Pessoa. Aline Lima Pestana Magalhães. Laísa Fischer Wachholz. Patricia Treviso.

Redação e revisão crítica do manuscrito: Sibele Maria Schuantes Paim. Neide da Silva Knihs. João Luis Erbs Pessoa. Aline Lima Pestana Magalhães. Laísa Fischer Wachholz. Patricia Treviso.

Aprovação da versão final do manuscrito: Sibele Maria Schuantes Paim. Neide da Silva Knihs. João Luis Erbs Pessoa. Aline Lima Pestana Magalhães. Laísa Fischer Wachholz. Patricia Treviso.

Responsabilidade por todos os aspectos do conteúdo e a integridade do artigo publicado. Sibele Maria Schuantes Paim. Neide da Silva Knihs. João Luis Erbs Pessoa. Aline Lima Pestana Magalhães. Laísa Fischer Wachholz. Patricia Treviso.

\section{EDITOR ASSOCIADO}

\author{
Antonio José Almeida Filho (1)
}

\section{EDITOR CIENTÍFICO}

\author{
Ivone Evangelista Cabral (D)
}

\section{REFERÊNCIAS}

1. Xu Z, Shi L, Wang Y, Zhang J, Huang L, Zhang C et al. Pathological findings of COVID-19 associated with acute respiratory distress syndrome. Lancet Respir Med. 2020;8(4):420-2. http://dx.doi.org/10.1016/S22132600(20)30076-X. PMid:32085846.

2. Wu F, Zhao S, Yu B, Chen YM, Wang W, Song ZG et al. A new coronavirus associated with human respiratory disease in China. Nature. 2020;579(7798):265-9. http://dx.doi.org/10.1038/s41586-020-2008-3. PMid:32015508.

3. Ministério da Saúde (BR). Nota Técnica no 25 de 2020 - CGSNT/ DAET/SAES/MS. Critérios técnicos para triagem clínica do coronavírus (SARS, MERS, SARS-CoV-2) nos candidatos à doação de órgãos e tecidos para manejo do paciente em lista de espera e do transplantado [Internet]. Brasília (DF): Ministério da Saúde;2020 [cited 2020 Nov 10]. Available from: https://portalarquivos.saude.gov.br/images/pdf/2020/ May/07/Nota-t--cnica-N---25-2020-CGSNT-DAET-SAES-MS.pdf

4. Tzedakis S, Jeddou H, Houssel-Debry P, Sulpice L, Boudjema K. COVID-19: thoughts and comments from a tertiary liver transplant center in France. Am J Transplant. 2020;20(7):1952-1953. http://dx.doi. org/10.1111/ajt.15918. PMid:32282972.

5. Pan L, Wang P, Huang $X$. How to face the novel coronavirus infection during the 2019-2020 epidemic: the experience of Sichuan Provincia People's Hospital. Intensive Care Med. 2020;46(4):573-5. http://dx.doi. org/10.1007/s00134-020-05964-0. PMid:32072300.

6. Zhang BH, Yan LN, Yang JY. Organ transplantation management in the midst of the COVID-19 outbreak: a synopsis. HBSN. 2020;9(2):250-2. http://dx.doi.org/10.21037/hbsn.2020.03.16.

7. World Health Organization. The Conceptual Framework for the International Classification for Patient Safety. Version 1.1. Final Technical Report and Technical Annexes [Internet]. Geneva:WHO; 2009 [citado 2020 nov 10]. Disponível em: https://portaldeboaspraticas.iff.fiocruz.br/wp-content/ uploads/2019/07/WHO_IER_PSP_2010.2_eng.pdf

8. Ministério da Saúde (BR). Agência Nacional de Vigilância Sanitária. Guia de Biovigilância de Células, Tecidos e Órgãos e Manual de Notificação [Internet]. Brasília (DF), 2016 [citado 2020 nov 10]. Disponível em: http:// antigo.anvisa.gov.br/documents/33868/3055469/Guia+de+Biovigil\%C3\% A2ncia+de+C\%C3\%A9lulas $\% 2 \mathrm{C}+$ Tecidos+e+\%C3\%93rg\%C $3 \%$ A3os+\%26+Manual+ de+Notifica\%C3\%A7\%C3\%A3o/bfe $1 f 75$ d-4351-4ca9-b56d-54c985213154

9. Resolução da Diretoria Colegiada no 339 , de 20 de fevereiro de 2020 (BR). Dispõe sobre a instituição do Sistema Nacional de Biovigilância. Diário Oficial da União, Brasília (DF) [periódico na internet], 2020: Seção 1 [citado 2020 nov 10]. Disponível em: https://www.in.gov.br/ web/do u/-/re solucao-de-diretoria-cole giada- rdc-n-339-de-20-de-fe vereiro-de-2020-244864047

10. Magalhães ALP, Lanzoni GMM, Knihs NS, Silva EL, Erdmann AL. Patient safety in the process of organ and tissue donation and transplant. Cogitare Enferm. 2017;22(2):e45621. http://dx.doi.org/10.5380/ce.v22i1.45621.

11. Associação Brasileira de Transplante de Órgãos. Transplante e coronavírus [Internet]. São Paulo: ABTO; 2020 [citado 2020 nov 10] Disponível em: http://www.abto.org.br/abtov03/default.as px?mn=4 $87 \& \mathrm{c}=0 \& \mathrm{~s}=156 \& \mathrm{pop}=$ true

12. Ministério da Saúde (BR). Agência Nacional de Vigilância Sanitária. Nota Técnica GVIMS/GGTES/ANVISA № 04/2020. Orientações para serviços de saúde: medidas de prevenção e controle que devem ser adotadas durante a assistência aos casos suspeitos ou confirmados de infecção pelo novo coronavírus (SARS-CoV-2) [Internet]. Brasília (DF): Ministério da Saúde; 2021 [citado 2020 nov 10]. Disponível em: https://www.gov.br/anvisa /pt-br/centraisdeconteudo/publicacoes/ 
servicosdesaude/notas-tecnicas/nota-tecnica-gvims _ggtes_anvisa04_2020-25-02-para-o-site.pdf

13. Maben J, Bridges JB. Covid-19: supporting nurses' psychological and mental health. J Clin Nurs. 2020 ago;29(15-16):2742-50. http://dx.doi. org/10.1111/jocn.15307. PMid:32320509.

14. Bardin L. Análise de conteúdo. São Paulo: Edições 708; 2011.

15. Oliveira AC, Lucas TC, Iquiapaza RA. What has the covid-19 pandemic taught us about adopting preventive measures? Texto Contexto Enferm. 2020;29:e20200106. http://dx.doi.org/10.1590/1980-265x-tce-2020-0106.

16. Santana N, Costa GA, Costa SSP, Pereira LV, Silva JV, Sales IPPM. Segurança dos profissionais de saúde no enfrentamento do novo coronavírus no Brasil. Esc Anna Nery. 2020;24(spe):e20200241. http:// dx.doi.org/10.1590/2177-9465-ean-2020-0241.

17. Pessoa JLE, Knihs NS, Magalhães ALP, Schuantes-Paim SM, Fischer L, Roza BA. Coronavirus infections: recommendations for good practice in obtaining tissues and organs for the transplantation. SciELO Preprints. No prelo 2020. http://dx.doi.org/10.1590/SciELOPreprints.855.

18. Carvalho EC, Oliveira-Kumakura ARS, Morais SCRV. Clinical reasoning in nursing: teaching strategies and assessment tools. Rev Bras Enferm. 2017;70(3):662-8. http://dx.doi.org/10.1590/0034-7167-2016-0509. PMid:28562818.

19. Menegon FHA, Santos JLG, Gonçalves N, Kahl C, Barreto MS, Gelbcke FL. Development of the clinical reasoning of nurses of an emergency hospital service. Rev Rene (Online). 2019;20(1):e40249. http://dx.doi. org/10.15253/2175-6783.20192040249.

20. Westphal GA, Veiga VC, Franke CA. Determinação da morte encefálica no Brasil. Rev Bras Ter Intensiva. 2019;31(3):403-9. http://dx.doi. org/10.5935/0103-507X.20190050. PMid:31618361.

21. Resolução da Diretoria Colegiada oㅜ 36 de 25 de julho de 2013 (BR) Institui ações para a segurança do paciente em serviços de saúde $e$ dá outras providências. Diário Oficial da União [periódico na internet], Brasília (DF), 2013 [citado 2020 nov 10]. Disponível em: https://bvsms. saude.gov.br/bvs/saudelegis/anvisa/2013/rdc0036_25_07_2013.html

22. Souza CS, Tomaschewski-Barlem JG, Dalmolin GL, Silva TL, Neutzling BRS, Zugno RM. Strategies for strengthening safety culture in intensive care units. Rev enferm UERJ. 2019;27:e38670. http://dx.doi.org/10.12957/ reuerj.2019.38670.

23. Decreto $\mathrm{n}^{0} 9.175$, de 18 de outubro de 2017 (BR). Regulamenta a lei $\mathrm{n}^{\circ}$ 9.434, de 4 de fevereiro de 1997, para tratar da disposição de órgãos, tecidos, células e partes do corpo humano para fins de transplante e tratamento. Diário Oficial da União [periódico na internet], Brasília (DF), 2017 [citado 2020 nov 10]. Disponível em: https://legislacao.presidencia. gov.br/atos/? tipo=DEC\&nu mero=9175\&ano=2017\&ato=eec ETSU1UeZp W Tda5\#: :text= Ementa\%3A,FINS \%20DE\%20TRANSPLANTE\%2 OE\%2OTRATAMENTO

24. Treviso P, Peres SC, Silva AD, Santos AA. Competências do enfermeiro na gestão do cuidado. Rev Adm Saúde. 2017;17(69):10-5. http://dx.doi org/10.23973/ras.69.59. 